\title{
Central and peripheral relationships between morphine and glucose on antinociception in rats
}

Rinah T. Yamamoto* and Robin B. Kanarek

*Correspondence: yamamoto@mclean.harvard.edu

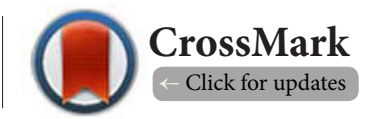

Department of Psychology, Tufts University, Medford, MA 02155, USA.

\begin{abstract}
Previous research from our laboratory has determined that in the absence of a gustatory response or taste hedonics, intraperitoneal (i.p.) glucose administration enhanced morphine-mediated analgesia in rats and had antinociceptive actions on its own. Two experiments examined the potential of a central mechanism for glucose's actions on morphine-mediated antinociception. Morphine $(2.5 \mu \mathrm{g})$ was infused into the periaqueductal gray $(\mathrm{PAG})$ while glucose $(300 \mathrm{mg} / \mathrm{kg})$ was injected into the peritoneal cavity, or glucose (32 nmol) was infused into the PAG while morphine $(3.2 \mathrm{mg} / \mathrm{kg}$ ) was injected i.p. Doses of morphine and glucose were selected based on our own prior research for being below the threshold for analgesic efficacy. Antinociception was assessed using the hot-water tail-withdrawal procedure. Tail-withdrawal latency was tested at baseline (before), and 12, 24 and 36 minutes after the i.p. injection. The results indicated that 300 $\mathrm{mg} / \mathrm{kg}$ glucose, administered i.p. effectively increased the antinociceptive potency of a low dose of centrally administered morphine, while central infusion of glucose enhanced peripheral morphine-mediated antinociception. These outcomes support previous evidence of glucose's influence on the antinociception actions of opioid drugs. Furthermore, they suggest that glucose produces its enhancing actions on morphine-mediated antinociception in the brain. These results support the hypothesis that glucose does not need to go through a gustatory mechanism or taste hedonics to alter morphine's antinociceptive actions.
\end{abstract}

Keywords: Antinociception, glucose, morphine, periaqueductal gray

\section{Introduction}

Intake of palatable sweet-tasting substances, such as sucrose and glucose solutions, can alter behavioral and physiological responses to opioid drugs in animals [1-3]. However, the specific effect of sweet tasting substances on these responses is not consistent, but rather varies as a function of the nutritive value of the palatable food or fluid. For example, intake of nutritive sweettasting solutions enhances morphine-mediated antinociception (MMA) while intake of non-nutritive sweet-tasting solutions is without effect [4-6]. Furthermore, acute consumption of a sucrose solution alone produces antinociceptive behavior that is reduced in the presence of $\mu$ opiate receptor antagonists, suggesting involvement of the endogenous opioid system $[3,7,8]$.

An important question to be addressed is the mechanism underlying the effects of nutritive sweet-tasting solutions on the actions of opiate drugs. Some researchers maintain that sweet substances alter MMA through taste hedonics and gustatory signals that are transmitted to the central nervous system [9-13]. However, sweet substances might also have more general physiological consequences. One way to determine if the effects of intake of sweet substances are due to their hedonic properties or reflect a more systemic action would be to bypass gustatory responses by administering a sweet solution directly into the peritoneal cavity. Research from our laboratory has shown that an intraperitoneal injection of glucose, which serves as a primary energy source for metabolic processes in both the periphery and central nervous system, enhances the antinociceptive properties of the $\mu$-opioid agonist, morphine [14]. Moreover, intraperitoneal glucose administration, on its own, produces antinociceptive actions in rats that can be measured using the hot-water tail-withdrawal procedure [14]. These results imply that the alteration in MMA seen in rats consuming palatable solutions is not simply a consequence of the hedonic properties of the solution [15]. 
In two pilot studies, a low dose of morphine was administered into either, the lateral ventricles (i.c.v.) or peritoneal cavity (i.p.) of rats, while a low dose of glucose was administered into the peritoneal cavity or lateral ventricles, respectively. In both pilot studies, glucose and morphine at doses that did not produce antinociception on their own, produced a significant increase in tail withdrawal latency in the hot water tail withdrawal test when combined [16].

To further investigate whether the antinociceptive actions of glucose are mediated within the central nervous system, low doses of morphine (or glucose) were infused into the PAG of rats concomitant with low doses of glucose (or morphine) injected into the peritoneal cavity followed by an assessment of morphine-mediated antinociception. The PAG is associated with both opiates and pain. It is not only an important brain-site relaying nociceptive information but also has a high density of $\mu$-opiate receptors [17-21]. We hypothesized that administration of low doses of morphine and glucose alone would not produce antinociception while central and peripheral co-administration of glucose and morphine would produce antinociception. If, at low doses, peripheral or central glucose administration potentiates the antinociceptive actions of a central or peripheral morphine injection, respectively, this would provide evidence that glucose is altering MMA through a central mechanism.

\section{Methods}

\section{Animals}

Adult male Long-Evans rats (Charles River Breeding Laboratories, Portage, MI) weighing 250-275 g at the start of the experiment were used. Rats were housed individually in standard stainlesssteel cages in a temperature-controlled room $\left(22 \pm 1^{\circ} \mathrm{C}\right)$ maintained on a reverse 12-12 hr light-dark cycle (lights on: 2000-0800 hr). Rats had unrestricted access to standard Purina Rodent Pellets (\#5001) and water. All rats were allowed to acclimate to the laboratory and handling procedures for at least one week prior to the initiation of experimental procedures. Rats were handled daily by the same experimenter to reduce the possibility of stressrelated behaviors during antinociceptive testing. All testing took place during the dark phase of the 24-hour cycle.

These studies were carried out in accordance with the NIH Guidelines for the Care of Laboratory Animals. The Tufts University Institutional Animal Care and Use Committee approved all of the experimental protocols. All efforts were made to minimize animal suffering and to keep the number of animals used to the minimum necessary.

\section{Surgery}

Surgery was performed at least one week after the rats were delivered to the laboratory. Rats were anesthetized with $6 \mathrm{mg} /$ $\mathrm{kg}$ xylazine in combination with $100 \mathrm{mg} / \mathrm{kg}$ ketamine administered i.p. Using a stereotaxic apparatus, stainless steel guide cannulae (Plastics One, Roanoke, VA) were implanted into the PAG (from bregma -7.6 AP, -0.8 ML and -5.8 DV) [22].
Dummy cannulae were inserted to maintain cannulae guide integrity. Immediately following surgery, rats were administered $20 \mathrm{mg} / \mathrm{kg}$ cefazolin antibiotic, intramuscularly, and allowed to recover in their home cages for a minimum of one week prior to antinociceptive testing.

\section{Drugs}

For peripheral administration, morphine sulfate (generously donated by the National Institute on Drug Abuse) was dissolved in $0.9 \%$ saline to a concentration of $3.2 \mathrm{mg} / \mathrm{ml}$ and administered i.p. in a volume of $1.0 \mathrm{ml} / \mathrm{kg}$. For PAG administration, $2.5 \mu \mathrm{g}$ morphine sulfate was dissolved in $0.5 \mu \mathrm{l} 0.9 \%$ saline.

For peripheral administration, D-glucose (ICN Biomedicals) was dissolved in sterile water at a concentration of $300 \mathrm{mg} / \mathrm{ml}$ (1.665 molar concentration), and administered i.p. in a volume of $1.0 \mathrm{ml} / \mathrm{kg}$. For PAG administration, D-glucose was dissolved in sterile water to produce $32 \mathrm{nmol}$. While there is some inconsistency in the literature on the morphine dose threshold for antinociception, the morphine and glucose doses used in the current studies were selected based on research on MMA [23-30] and by our own prior research on both MMA and glucosemediated antinociception [14].

Morphine and glucose, or their respective vehicles, were infused into the PAG through a 28-gauge internal injection cannula extending $0.1 \mathrm{~mm}$ beyond the guide cannula. The internal cannula was connected using PVC (\#32) tubing filled with morphine, glucose, physiological saline or sterile water and infused using a gas tight $25 \mu \mathrm{g}$ Hamilton syringe and a Harvard infusion pump. The infusion volume was $0.5 \mu \mathrm{l}$ for PAG injections delivered over one minute. Cannulae were left in situ for $30 \mathrm{~s}$ following drug infusions.

\section{Determination of antinociceptive responses}

Each rat was gently held in a clean towel and placed on a platform, level with the top of a hot-water bath maintained at $54 \pm 0.2^{\circ} \mathrm{C}$. The rat's tail was gently lowered $4 \mathrm{~cm}$ into the hot water bath. The behavioral response criterion was removal of the tail from the hot water bath. To prevent tissue damage if a rat failed to remove its tail within $12 \mathrm{~s}$, the tail was gently removed from the water bath by the experimenter [31]. Tail withdrawal latency was measured to the nearest 0.1 second using a stopwatch. Antinociceptive testing was performed prior to drug administration (baseline) and at 12, 24, and 36 minutes after drug injections.

\section{Effects of morphine administration into the PAG and intraperitoneal glucose injections on antinociceptive responses}

Following determination of baseline tail-withdrawal latencies, drug-naïve rats were infused with morphine or saline into the PAG followed immediately by i.p. injections of glucose or sterile water. Eight rats received injections of $2.5 \mu \mathrm{g}$ morphine PAG+300 $\mathrm{mg} / \mathrm{kg}$ glucose i.p. eight rats, $2.5 \mu \mathrm{g}$ morphine PAG+sterile water i.p. eight rats, saline $\mathrm{PAG}+300 \mathrm{mg} / \mathrm{kg}$ glucose i.p. and eight rats, 
saline PAG+sterile water i.p.

\section{Effects of glucose administration into the PAG and intraperitoneal morphine injections on antinociceptive responses}

Following determination of baseline tail-withdrawal latencies, drug-naïve rats were infused with glucose or sterile water in the PAG followed immediately by i.p. morphine or saline in jections. Eight rats received injections of $32 \mathrm{nmol}$ glucose into the PAG+3.2 mg/kg morphine i.p. eight rats, sterile water into the PAG+3.2 mg/kg morphine i.p. seven rats, $32 \mathrm{nmol}$ glucose into the PAG+saline i.p. and seven rats, sterile water into the PAG+saline, i.p.

\section{Histology}

After the conclusion of each experiment, rats were euthanized with carbon dioxide and the brains removed immediately and placed in a $4 \%$ paraformaldahyde solution. Brains were subsequently sectioned into 40-micron slices, stained with cresyl violet and assessed for cannulae placement. Rats with incorrect cannulae placements were removed from analyses.

\section{Statistical analysis}

Antinociceptive responses are expressed as percent maximal possible effect (\%MPE) using the formula (Dewey and Harris, 1975):

$$
\% M P E=\frac{\text { test latency }- \text { baseline latency }}{\text { maximal latency }(12 s)-\text { baseline latency }} \times 100
$$

Repeated-measures ANOVAs were used to analyze \%MPEs across time, using morphine and glucose doses as betweensubjects factors and time after glucose administration as the within-subjects factor. Post-hoc comparisons were assessed with Bonferroni t-test to assess group differences.

\section{Results \\ Effects of an injection of $2.5 \mu \mathrm{g}$ morphine into the PAG with an intraperitoneal injection of $300 \mathrm{mg} /$ $\mathrm{kg}$ glucose on antinociceptive responses}

Histology confirmed that cannulae were in the PAG in all but four rats, which were removed from the data.

There were no significant differences in baseline tail-withdrawal latencies among the groups prior to drug injections (mean \pm standard deviation (sd): PAG saline with i.p. sterile water $3.3 \pm 1.0 \mathrm{sec}$, PAG saline with i.p. glucose $3.3 \pm 0.6 \mathrm{sec}$, PAG morphine with i.p. sterile water $3.5 \pm 0.7 \mathrm{sec}$ and PAG morphine with i.p. glucose $2.7 \pm 0.4 \mathrm{sec}$ ).

Across the three measurement times, antinociceptive responses of rats that received an injection of $2.5 \mu \mathrm{g}$ morphine into the PAG and i.p. injection of $300 \mathrm{mg} / \mathrm{kg}$ glucose were significantly greater than those of animals in all other drug combinations $\left(\mathrm{F}_{3,24}=1.83, \mathrm{p}<0.0001\right.$; partial $\left.\eta^{2}=0.6\right)$. Post-hoc Bonferroni t-tests revealed that \%MPEs were significantly greater for rats receiving an injection of $2.5 \mu \mathrm{g}$ morphine into the PAG and i.p. injection of $300 \mathrm{mg} / \mathrm{kg}$ glucose than for rats that received an injection of
$2.5 \mu \mathrm{g}$ morphine into the PAG and i.p. injection of sterile water, or an injection of saline into the PAG and an i.p. injection or either glucose or saline. The lack of efficacy of the morphine infusion on its own or the glucose injection alone confirmed that these doses were below the analgesic thresholds for these substances and is consistent with our prior research [14]. Additionally, one-way ANOVAs demonstrated that at 12, 24 and 36 minutes after injections, \%MPEs for rats co-administered morphine into the PAG and glucose into the peritoneal cavity were significantly greater than \%MPEs for rats receiving any other drug combination (\%MPE 12 min, $\mathrm{F}_{3,24}=5.77$; \%MPE 24 $\min , \mathrm{F}_{3,24}=14.99$; \%MPE $36 \mathrm{~min}, \mathrm{~F}_{3,24}=5.67$; all $\mathrm{p}$ values $<0.01$ ) (Figure 1).

Effects of an injection of $32 \mathrm{nmol}$ glucose into the PAG with an intraperitoneal injection of $3.2 \mathrm{mg} / \mathrm{kg}$ morphine on antinociceptive responses

Histology confirmed that cannulae were located in the PAG in all but three rats, which were removed from the data analyses.

There were no significant differences in baseline tail-withdrawal latencies between the groups that subsequently received injections of $32 \mathrm{nmol}$ glucose or sterile water into the PAG and i.p. injections of either $3.2 \mathrm{mg} / \mathrm{kg}$ morphine or saline (mean \pm sd: PAG sterile water with i.p. saline $3.2 \pm 0.7 \mathrm{sec}$, PAG sterile water with i.p. morphine $3.4 \pm 0.6 \mathrm{sec}$, PAG glucose with i.p. saline $2.8 \pm 0.6 \mathrm{sec}$ and PAG glucose with i.p. morphine $3.3 \pm 0.7 \mathrm{sec}$ ).

Repeated-measures ANOVA determined that there was a significant group by time interaction $\left(\mathrm{F}_{6,46}=3.21, \mathrm{p}<0.01\right.$; partial $\eta^{2}=0.3$ ) (Figure 2). There was a significant main effect for drug

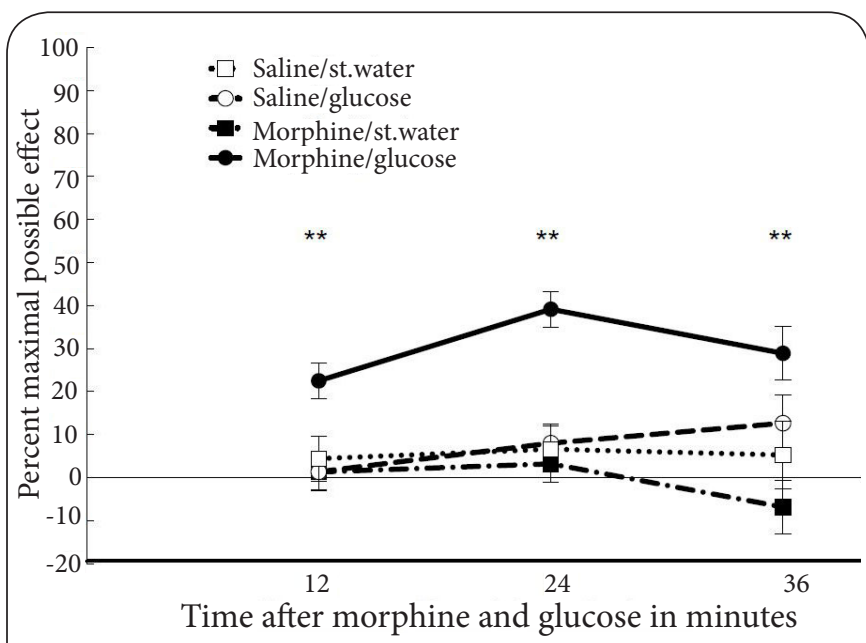

Figure 1. Antinociceptive responses on the hot water tail withdrawal test in rats following injections of $2.5 \mu \mathrm{g}$ morphine or saline into the PAG and i.p. injections of $300 \mathrm{mg} / \mathrm{kg}$ glucose or sterile water. Glucose significantly enhanced antinociceptive responding following administration of morphine into the PAG relative to rats in the other drug conditions. Values represent percent maximal possible effect with error bars representing standard error of the mean. Significant differences at $p<0.01$ are marked with a double asterisk $\left.{ }^{* *}\right)$. 
group $\left(\mathrm{F}_{3,23}=15.08, \mathrm{p}<0.0001 ;\right.$ partial $\left.\eta^{2}=0.7\right)$. Post-hoc Bonferroni t-tests indicated that the $32 \mathrm{nmol}$ glucose (PAG) and 3.2 $\mathrm{mg} / \mathrm{kg}$ morphine (i.p.) combination increased \%MPEs in rats relative to all other drug combinations (all p values $<0.003$ ). One-way ANOVAs demonstrated that at 12, 24 and 36 minutes after injections, \%MPEs for rats co-administered glucose into the PAG and morphine into the peritoneal cavity were significantly greater than \%MPE for rats receiving any other drug combination (\%MPE 12 min, $\mathrm{F}_{3,23}=3.74, \mathrm{p}<0.025$; \%MPE 24 min, $\mathrm{F}_{3,23}=9.78, \mathrm{p}<0.0001$; \%MPE $\left.36 \mathrm{~min}, \mathrm{~F}_{3,23}=8.09, \mathrm{p}<0.001\right)$.

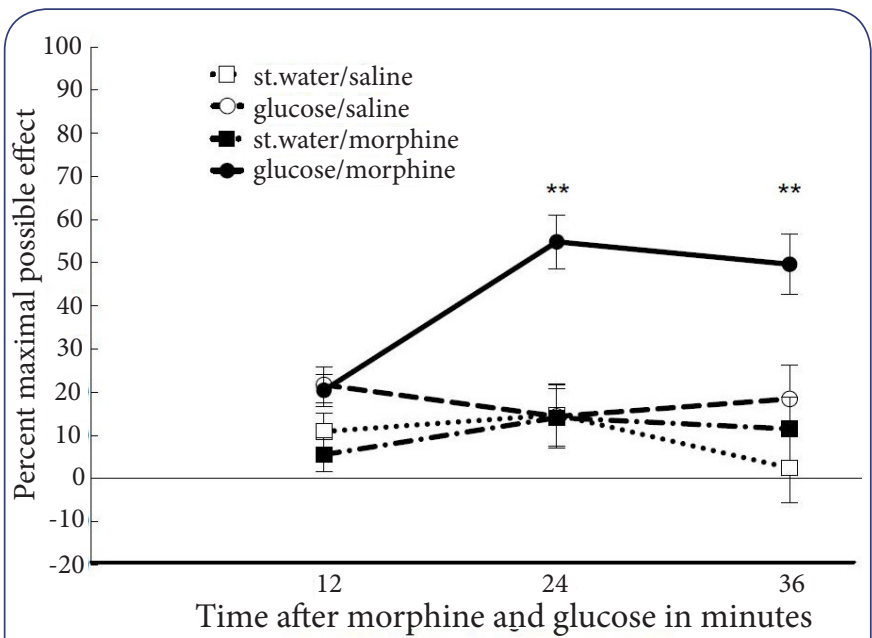

Figure 2. Antinociceptive responses in rats on the hot water tail withdrawal test following administration of $32 \mathrm{nmol}$ glucose into the PAG or sterile water and i.p. injections of 3.2 $\mathrm{mg} / \mathrm{kg}$ morphine or saline. Glucose in the PAG significantly enhanced antinociceptive responding following i.p. injections of morphine, relative to rats in the other drug conditions. Values represent percent maximal possible effect with error bars representing standard error of the mean. Significant differences at $\mathrm{p}<0.01$ are marked with a double asterisk ${ }^{* *}$.

\section{Discussion}

These experiments demonstrate that in the absence of gustatory input, glucose modulates the antinociceptive actions of both centrally and peripherally administered morphine in rats. A low dose of morphine $(2.5 \mu \mathrm{g})$ infused into the PAG or administered peripherally (3.2 $\mathrm{mg} / \mathrm{kg}$ i.p.) was not sufficient on its own to produce an antinociceptive response. However, a significant antinociceptive response was observed when glucose $(300 \mathrm{mg} /$ $\mathrm{kg}$ i.p. or $32 \mathrm{nmol}$ PAG) was co-administered with morphine. These results support our preliminary results and validate our hypotheses. To our knowledge, this is the first report of this effect.

Numerous studies have examined the effects of palatable sweet substances on the analgesic actions of opiate receptor agonists such as morphine [6,32-34]. Findings from these studies show that intake of sweet substances enhances morphine-mediated MMA. It has been suggested that palatability and hedonics play a role in the ability of sweet substances to alter morphinemediated antinociception $[\mathbf{1 0 - 1 3 , 3 5 ] . ~ T h i s ~ s t u d y ~ c i r c u m v e n t e d ~}$ the effects of palatability and hedonics by administering glucose directly into the peritoneal cavity or into the PAG, a region rich in opiate receptors. Thus our results imply that glucose influences antinociceptive activity, independent of its palatability and hedonic value.

Mechanisms that could account for the present observations include glucose modulation of receptor binding, endogenous opioid levels, or receptor affinity. Rats consuming sugar solutions demonstrate increased opiate receptor binding [5,36-38]. Further, sucrose ingestion has been linked to increased $\boldsymbol{\beta}$-endorphin release $[39,40]$ and enhanced c-Fos immunoreactive response, a marker of neuronal excitation, to naloxone [13], an opiate receptor antagonist. Sucrose also inhibits opioid receptor internalization, which would increase the number of available receptors, thus reducing the concentration of morphine needed to produce an effect [41-43].

In the present studies, co-administration of very low antinociceptive doses of morphine and glucose, via combinations of central and peripheral routes, produced antinociceptive behavioral responses. This confirms prior data that includes evidence that i.p. glucose has antinociceptive actions on its own [14]. In that study, we did not note a dose-response profile for glucose on antinociception. A review of the literature to date has shown that ours is the only laboratory reporting research on the analgesic properties of glucose by itself. In addition to our own laboratory, other researchers have investigated antinociceptive behaviors relating to combinations of sucrose (feeding) and MMA [for examples see; 44-47].

\section{Competing interests}

The authors declare that they have no competing interests.

\section{Authors' contributions}

Dr. Yamamoto, as a doctoral student under the advisorship of Dr. Kanarek, designed and executed the research, analyzed the data and wrote the manuscript. Dr. Kanarek provided input into the study design, advise throughout the process and contributed to the writing of the manuscript.

\section{Acknowledgement}

This work was supported by an Individual National Research Service Award (grant 5 F31 DA15258) from the National Institutes on Drug Abuse at the National Institutes of Health, to R. T. Yamamoto, a predoctoral trainee, under the sponsorship of R. B.Kanarek; grant 5 R01 DA004132, National Institutes on Drug Abuse.

\section{Publication history}

Editors: Vinay Parikh, Temple University, USA.

Giovanni Laviola, Istituto Superiore di Sanità, Italy.

Received: 16 October 2014 Revised: 05 December 2014

Accepted: 19 December 2014 Published: 26 December 2014

\section{References}

1. Ragozzino ME, Arankowsky-Sandoval G and Gold PE. Glucose attenuates the effect of combined muscarinic-nicotinic receptor blockade on spontaneous alternation. Eur J Pharmacol. 1994; 256:31-6. | Aritcle | PubMed

2. Rudski JM, Billington $\mathrm{CJ}$ and Levine AS. A sucrose-based maintenance diet increases sensitivity to appetite suppressant effects of naloxone. 
Pharmacol Biochem Behav. 1997; 58:679-82. | Aritcle | PubMed

3. Rani $S$ and Gupta MC. Evaluation and comparison of antinociceptive activity of aspartame with sucrose. Pharmacol Rep. 2012; 64:293-8. Pdf | PubMed

4. D'Anci KE, Kanarek RB and Marks-Kaufman R. Beyond sweet taste: saccharin, sucrose, and polycose differ in their effects upon morphineinduced analgesia. Pharmacol Biochem Behav. 1997; 56:341-5. | Aritcle I PubMed

5. Kanarek RB, Przypek J, D’Anci KE and Marks-Kaufman R. Dietary modulation of $\mathrm{mu}$ and kappa opioid receptor-mediated analgesia. Pharmacol Biochem Behav. 1997; 58:43-9. | Aritcle | PubMed

6. Kanarek RB, White ES, Biegen MT and Marks-Kaufman R. Dietary influences on morphine-induced analgesia in rats. Pharmacol Biochem Behav. 1991; 38:681-4. | Aritcle | PubMed

7. de Freitas RL, Kubler JM, Elias-Filho DH and Coimbra NC. Antinociception induced by acute oral administration of sweet substance in young and adult rodents: the role of endogenous opioid peptides chemical mediators and mu(1)-opioid receptors. Pharmacol Biochem Behav. 2012; 101:265-70. | Aritcle | PubMed

8. Shahlaee A, Farahanchi A, Javadi S, Delfan B and Dehpour AR. Sucroseinduced analgesia in mice: role of nitric oxide and opioid receptormediated system. Indian J Pharmacol. 2013; 45:593-6. | Aritcle | PubMed Abstract | PubMed FullText

9. Blass EM. Changing influences of sucrose and visual engagement in 2-to 12-week-old human infants: Implications for maternal face recognition. Infant Behav Dev. 1997; 20:423-34.

10. Blass EM and Watt LB. Suckling- and sucrose-induced analgesia in human newborns. Pain. 1999; 83:611-23. | Aritcle | PubMed

11. Fontella FU, Nunes ML, Crema LM, Balk RS, Dalmaz C and Netto CA. Taste modulation of nociception differently affects chronically stressed rats. Physiol Behav. 2004; 80:557-61. | Aritcle | PubMed

12. Le Magnen J, Marfaing-Jallat $P$, Miceli $D$ and Devos M. Pain modulating and reward systems: a single brain mechanism? Pharmacol Biochem Behav. 1980; 12:729-33. | Aritcle | PubMed

13. Pomonis JD, Jewett DC, Kotz CM, Briggs JE, Billington CJ and Levine AS. Sucrose consumption increases naloxone-induced c-Fos immunoreactivity in limbic forebrain. Am J Physiol Regul Integr Comp Physiol. 2000; 278:R712-9. | Aritcle | PubMed

14. Yamamoto RT, Foulds-Mathes $W$ and Kanarek RB. Antinociceptive actions of peripheral glucose administration. Pharmacol Biochem Behav. 2014; 117:34-9. | Aritcle | PubMed Abstract | PubMed FullText

15. Sunram-Lea SI, Foster JK, Durlach P and Perez C. The effect of retrograde and anterograde glucose administration on memory performance in healthy young adults. Behav Brain Res. 2002; 134:505-16. | Aritcle | PubMed

16. Yamamoto RT and Kanarek RB. Intraperitoneal glucose administration boosts the antinociceptive potency of central morphine administration. Society for Neuroscience. San Diego. 2004.

17. Fabian I and Ableitner A. Brain sites involved in mu-opioid receptormediated actions: a 2-deoxyglucose study. Brain Res. 1995; 697:205-15. | Aritcle | PubMed

18. Kai Y, Oomura Y and Shimizu N. Responses of rat lateral hypothalamic neurons to periaqueductal gray stimulation and nociceptive stimuli. Brain Res. 1988; 461:107-17. | Aritcle | PubMed

19. Mansour A, Fox CA, Akil $H$ and Watson SJ. Opioid-receptor mRNA expression in the rat CNS: anatomical and functional implications. Trends Neurosci. 1995; 18:22-9. | Aritcle | PubMed

20. Wang $\mathrm{H}$ and Wessendorf MW. Mu- and delta-opioid receptor mRNAs are expressed in periaqueductal gray neurons projecting to the rostral ventromedial medulla. Neuroscience. 2002; 109:619-34. | Aritcle | PubMed

21. Yaksh TL, Al-Rodhan NRF and Jensen T. Sites of action of opiates in production of analgesia. In: Fields $\mathrm{HL}$, Besson JM, editors. Prog Brain Res: Elsevier Science Publishers B. V. (Biomedical Division). 1988; 371-81.

22. Paxinos $G$ and Watson $C$. The rat brain in stereotaxic coordinates. 2 ed. San Diego, New York: Academic Press. 1986.
23. Ragozzino ME, Parker ME and Gold PE. Spontaneous alternation and inhibitory avoidance impairments with morphine injections into the medial septum. Attenuation by glucose administration. Brain Res. 1992; 597:241-9. | Aritcle | PubMed

24. Ragozzino ME and Gold PE. Glucose injections into the medial septum reverse the effects of intraseptal morphine infusions on hippocampal acetylcholine output and memory. Neuroscience. 1995; 68:981-8. | Aritcle | PubMed

25. Parent MB and Gold PE. Intra-septal infusions of glucose potentiate inhibitory avoidance deficits when co-infused with the GABA agonist muscimol. Brain Res. 1997; 745:317-20. | Aritcle | PubMed

26. Yamamoto RT. Glucose alters pain response and other opiate-related behaviors [Dissertation]. Medford, MA: Tufts University. 2005.

27. Bobeck EN, McNeal AL and Morgan MM. Drug dependent sexdifferences in periaqueducatal gray mediated antinociception in the rat. Pain. 2009; 147:210-6. | Aritcle | PubMed Abstract | PubMed FullText

28. Morgan MM, Fossum EN, Levine CS and Ingram SL. Antinociceptive tolerance revealed by cumulative intracranial microinjections of morphine into the periaqueductal gray in the rat. Pharmacol Biochem Behav. 2006; 85:214-9. | Aritcle | PubMed

29. Satoh M, Kubota A, Iwama T, Wada T, Yasui M, Fujibayashi K and Takagi $\mathrm{H}$. Comparison of analgesic potencies of mu, delta and kappa agonists locally applied to various CNS regions relevant to analgesia in rats. Life Sci. 1983; 33 Suppl 1:689-92. | Aritcle | PubMed

30. Siuciak JA and Advokat C. Tolerance to morphine microinjections in the periaqueductal gray (PAG) induces tolerance to systemic, but not intrathecal morphine. Brain Res. 1987; 424:311-9. | Aritcle | PubMed

31. Janssen PA, Niemegeers $\mathrm{CJ}$ and Dony JG. The inhibitory effect of fentanyl and other morphine-like analgesics on the warm water induced tail withdrawl reflex in rats. Arzneimittelforschung. 1963; 13:502-7. | PubMed

32. Calcagnetti DJ and Holtzman SG. Intake of sweet water attenuates restraint-stress-induced potentiation of morphine analgesia in rats. Brain Res Bull. 1992; 29:859-64. | Aritcle | PubMed

33. Kanarek RB, Mathes WF, Heisler LK, Lima RP and Monfared LS. Prior exposure to palatable solutions enhances the effects of naltrexone on food intake in rats. Pharmacol Biochem Behav. 1997; 57:377-81. | Aritcle I PubMed

34. Roane DS and Martin RJ. Continuous sucrose feeding decreases pain threshold and increases morphine potency. Pharmacol Biochem Behav. 1990; 35:225-9. | Aritcle | PubMed

35. Blass $E$, Fitzgerald $E$ and Kehoe P. Interactions between sucrose, pain and isolation distress. Pharmacol Biochem Behav. 1987; 26:483-9. | Aritcle | PubMed

36. Colantuoni C, Schwenker J, McCarthy J, Rada P, Ladenheim B, Cadet $\mathrm{JL}$, Schwartz GJ, Moran TH and Hoebel BG. Excessive sugar intake alters binding to dopamine and mu-opioid receptors in the brain Neuroreport. 2001; 12:3549-52. | Aritcle | PubMed

37. Gagin $R$, Cohen $E$ and Shavit $Y$. Prenatal exposure to morphine alters analgesic responses and preference for sweet solutions in adult rats. Pharmacol Biochem Behav. 1996; 55:629-34. | Aritcle | PubMed

38. Marks-Kaufman R, Hamm MW and Barbato GF. The effects of dietary sucrose on opiate receptor binding in genetically obese (ob/ob) and lean mice. J Am Coll Nutr. 1989; 8:9-14. | PubMed

39. Dum J, Gramsch C and Herz A. Activation of hypothalamic betaendorphin pools by reward induced by highly palatable food. Pharmacol Biochem Behav. 1983; 18:443-7. I PubMed

40. Yamamoto T, Sako N and Maeda S. Effects of taste stimulation on betaendorphin levels in rat cerebrospinal fluid and plasma. Physiol Behav. 2000; 69:345-50. | Aritcle | PubMed

41. Keith DE, Anton B, Murray SR, Zaki PA, Chu PC and Lissin DV et al. $\mu$-Opioid Receptor Internalization: Opiate Drugs Have Differential Effects on a Conserved Endocytic Mechanism In Vitro and in the Mammalian Brain. Mol Pharmacol. 1998; 53:377-84.

42. Kramer HK and Simon EJ. mu and delta-opioid receptor agonists induce mitogen-activated protein kinase (MAPK) activation in the absence 
Yamamoto et al. Journal of Psychiatry and Brain Functions 2014,

of receptor internalization. Neuropharmacology. 2000; 39:1707-19. | Aritcle | PubMed

43. Sternini C, Brecha NC, Minnis J, D'Agostino G, Balestra B, Fiori E and Tonini $\mathrm{M}$. Role of agonist-dependent receptor internalization in the regulation of mu opioid receptors. Neuroscience. 2000; 98:233-41. | Aritcle | PubMed

44. Mukherjee K, Mathur R and Nayar U. Effect of VMH lesion on sucroseFed nociceptive responses. Jpn J Physiol. 2000; 50:395-404. | Aritcle | PubMed

45. Mukherjee K, Mathur R and Nayar U. Ventromedial hypothalamic mediation of sucrose feeding induced pain modulation. Pharmacol Biochem Behav. 2001; 68:43-8. | Aritcle | PubMed

46. Mukherjee $K$, Mathur R and Nayar U. Hyperalgesic response in rats fed sucrose from weaning to adulthood: role of VMH. Pharmacol Biochem Behav. 2002; 73:601-10. | Aritcle | PubMed

47. Suri $M$, Jain $S$ and Mathur R. Pattern of biphasic response to various noxious stimuli in rats ingesting sucrose ad libitum. Physiol Behav. 2010; 101:224-31. | Aritcle | PubMed

48. NIDA. Prescription Pain and Other Medications. National Institute on Drug Abuse, National Institutes of Health, U.S. Department of Health and Human Services. 2001.

\section{Citation:}

Yamamoto R.T and Kanarek R.B. Central and peripheral relationships between morphine and glucose on antinociception in rats. J Psychiatry Brain Funct. 2014; 1:7. http://dx.doi.org/10.7243/2055-3447-1-7 